\title{
OS SISTEMAS LOCAIS DE AÇÃO PÚBLICA E A SUA ORIGEM NAS REDES SOCIOTÉCNICAS: A TERRITORIALIZAÇÃO DO PLANO BRASIL SEM MISÉRIA RURAL ${ }^{1}$
}

\author{
Daniela Aparecida Pacífico²
}

\begin{abstract}
RESUMO
Inseridos na perspectiva conhecida como abordagem pelos instrumentos, Pierre Lascoumes e Patrick Le Galès apresentam um enfoque que contribui para pensar a territorialização de políticas públicas. A abordagem considera que os processos de implementação de políticas públicas produzem sistemas locais de ação pública. Tais sistemas locais podem ser apreendidos a partir de quatro dimensões: da tradução e apropriação; do público; da mobilização dos atores; e da dimensão de tempo e lugar. Este trabalho apresenta e discute esta proposta e aplica este quadro analítico para o caso do Plano Brasil Sem Miséria Rural (BSM-Rural). Busca-se analisar se os sistemas locais produzidos pelo processo de implementação constituem-se das redes sociotécnicas existentes no norte do estado de Minas Gerais. Os dados apresentados que embasam este trabalho têm como fonte a análise de documentos e pesquisa de campo, na qual foram realizadas entrevistas semiestruturadas e observação participante. $O$ trabalho está dividido em cinco seções. A primeira faz uma introdução do tema; a seção seguinte debate a proposta analítica de Lascoumes e Le Galès; a terceira apresenta brevemente o BSM-Rural; a quarta analisa este programa à luz do quadro analítico e; por fim, são feitas algumas considerações finais. Conclui-se que os sistemas locais constituem-se das redes sociotécnicas existentes e, que, cada uma delas mobiliza, sobretudo, diferentes traduções e apropriações do BSM-Rural, possibilitando ajustes e criação de regras próprias de aplicação configurando particularidades à territorialização da ação pública.
\end{abstract}

Palavras-chave: pobreza rural, política pública, sociologia da ação pública.

\footnotetext{
${ }^{1}$ O presente trabalho é fruto da primeira etapa da pesquisa de campo realizada pela autora no âmbito da sua pesquisa de tese de doutorado (2012/2016). A primeira etapa foi realizada durante setembro e outubro de 2013, no norte do estado de Minas Gerais. Este trabalho, em sua forma preliminar, foi apresentado no $53^{\circ}$ Congresso da Sociedade Brasileira de Economia, Administração e Sociologia Rural (SOBER), em João Pessoa/PB, em julho de 2015.

${ }^{2}$ Graduada em Ciências Sociais (UEL). Mestre em Desenvolvimento Rural (UFRGS). Doutora em Ciências Sociais, Desenvolvimento e Sociedade (UFRRJ). Professora adjunta do Centro de Ciências Agrárias da Universidade Federal de Santa Catarina (UFSC).E-mail: daniela.pacifico@ufsc.br
} 


\title{
THE SYSTEMS LOCAL OF PUBLIC ACTION AND ORIGIN IN SOCIO-TECHNICAL NETWORKS: THE TERRITORIALIZATION OF PLAN BRAZIL WITHOUT RURAL POVERTY
}

\begin{abstract}
Inserted in the perspective known as approach by the instruments, Pierre Lascoumes and Patrick Le Galès present an approach that contributes to think the territorialization of public policies. The approach considers that the processes of implementation of public policies produce local systems of public action. Such local systems can be apprehended from four dimensions: translation and appropriation; the public; the mobilization of actors; and the dimension of time and place. This paper presents and discusses this proposal and applies this analytical framework to the case of the Brazil Without Rural Poverty Plan (BSM-Rural). The aim is to analyze if the local systems produced by the implementation process constitute the sociotechnical networks existing in the north of the state of Minas Gerais. The data presented in this paper are based on document analysis and field research, in which semi-structured interviews and participant observation were carried out. The work is divided into five sections. The first one introduces the theme; the following section discusses the analytical proposal of Lascoumes and Le Galès; the third briefly presents the BSM-Rural; the fourth examines this program in the light of the analytical framework; finally, some final considerations are made. It is concluded that the local systems constitute the existing socio-technical networks and that each of them mainly mobilizes different translations and appropriations of BSM-Rural, making possible adjustments and creation of own rules of application configuring particularities to the territorialization of the public action.
\end{abstract}

Keywords: public policy, rural poverty, sociology of public action.

\section{INTRODUÇÃO}

A temática da pobreza tem ocupado lugar de destaque nas agendas nacionais e internacionais e, desde a década de 1990, diversos programas e políticas públicas foram direcionados ao enfrentamento da pobreza, com destaque para a atuação dos organismos e agências de cooperação, bem como para o âmbito governamental em diversos países. No conjunto das inovações institucionais e das próprias políticas públicas na América Latina e Caribe, e paralelamente ao estabelecimento da democracia no final dos anos 1980, a convergência desse momento histórico contribuiu para a criação de um clima positivo que reforçou a importância e emergência de políticas públicas de enfrentamento da pobreza na primeira década dos anos 2000 . No Brasil foram desenvolvidas diversas ações pósredemocratização sendo a mais importante a campanha contra a fome e a miséria, expressa no Programa Fome Zero (LEITE, 2013).

No enfrentamento da pobreza diversas metodologias de mensuração têm sido utilizadas para dimensionar a grandeza de tal fenômeno. Segundo Mattei (2013, p. 102), praticamente todos os estudos, pesquisas e trabalhos acadêmicos têm como ponto de partida a renda monetária per capita das famílias. Até mesmo os trabalhos com abordagens diferenciadas como os baseados na perspectiva multidimensional acabam tomando a renda como critério básico para definir as 
populações pobres. Isso se deve ao fato de que as informações de renda estão mais disponíveis do que outras (MATTEI, 2013).

De modo geral, as referências disciplinares das políticas e programas de enfrentamento da pobreza vêm da economia e têm prestado pouca atenção à ligação entre o combate à pobreza e o desenvolvimento territorial. Tais referências se baseiam em metodologia de mensuração como as linhas de pobreza, por exemplo: a dollaraday, do Banco Mundial; índices de desenvolvimento; as metodologias derivadas das noções de pobreza absoluta e relativa, todas com enfoque de renda (MATTEI, 2013). Apesar disso, em correntes da economia não afeitas as formas convencionais de mensuração da pobreza, assim como em determinadas áreas das ciências sociais, identifica-se indicadores de saúde, educação, mobilidade, segurança alimentar e nutricional, laços e dinâmicas sociais e relações políticas como elementos constituintes da mensuração da pobreza, podendo expressar dimensões territoriais se considerados (BONNÁL, 2013).

Nesse sentido, no Brasil, estudos sobre desenvolvimento territorial e enfretamento da pobreza rural têm apresentado abordagens que têm considerado os atores locais como protagonistas de desenvolvimento, pertencentes a uma dinâmica territorial própria, fruto de relações sociais, de poder e dominação contextualizadas ${ }^{3}$. Está presente também a análise da concepção e estruturação dos programas, as novas institucionalidades, o peso das ideias, o papel das instituições e os interesses, a política da política, crítica à centralidade do Estado e suas ações top down, assim como os mercados, os movimentos sociais, sociedade civil organizada e participação, dentre outros temas. À vista disso, abre-se espaço para se analisar as formas como as políticas públicas são apropriadas pelos atores nos territórios e revelar as especificidades desse processo.

Por conseguinte, imbuído pelo desafio de pensar a territorialização das políticas públicas de enfrentamento da pobreza rural fugindo das referências monetárias utilizadas frequentemente e da centralidade do papel do Estado, este trabalho discute a perspectiva proposta por Pierre Lascoumes e Patrick Le Galès, em especial a contida no livro Sociologie de l'action publique ${ }^{4}$. Os autores destacam o processo de implementação das políticas públicas e partem do propósito de que analisá-la significa interessar-se pela forma que um programa público é apropriado, e não apenas pela forma como é concebido e estruturado.

O referencial da sociologia da ação pública - de onde se origina a abordagem pelos instrumentos ${ }^{5}$ - tem sido utilizado no Brasil no âmbito da discussão de direitos sociais e políticas sociais, ao que se refere à necessidade de considerar a grande diversidade de atores e as formas de mobilização que interagem e se articulam para resolver determinado problema público. Nesse sentido, o modelo clássico estado-centrista, de políticas públicas conduzidas exclusivamente pelo Estado estaria ultrapassado. Ainda no Brasil, este referencial também tem sido utilizado na interpretação de dinâmicas sociais de territórios amazônicos, para compreender as expressões entre a ação local e a constituição de novas territorialidades. Portanto, além de discutir o quadro de análise proposto pelos autores citados, este trabalho analisa se o processo de implementação do Plano

\footnotetext{
3 Ver estudos dos pesquisadores do Observatório de Políticas Públicas para Agricultura (OPPA), CPDA/UFRRJ e UFSC, na série Desenvolvimento Rural Sustentável, publicada pelo IICA.

${ }^{4}$ A primeira edição do Sociologie de l'action publique é de 2007, e a segunda de 2012. A versão em português do Sociologie de l'action publique está publicado pela Universidade Federal de Alagoas, pelo Laboratório de Direitos Humanos; e, a Introdução do Gouverner par lesinstruments, também em português no Dossiê territórios emergentes e ação pública, da Revista Pós Ciências Sociais, da Universidade Federal do Maranhão.

${ }^{5}$ No original, l'approche par lesinstruments.
} 
Brasil Sem Miséria Rural (BSM-Rural), no norte do estado de Minas Gerais, produz sistemas locais de ação pública e, se ao produzi-los, estes se constituem das redes sociotécnicas ${ }^{6}$ existentes.

O Plano Brasil Sem Miséria (PBSM), criado em 2011 pelo Governo Federal no âmbito do plano de erradicação da extrema pobreza - que se originou no escopo do Programa Fome Zero, objetivou promover a inclusão social e produtiva da população extremamente pobre, para tornar residual o percentual dos que viviam, à época, abaixo da linha da pobreza (MDS, 2015). Para isto três eixos orientaram as ações do Plano: o da garantia de renda; o de acesso a serviços; e o de inclusão produtiva, tanto para o rural como para o urbano.

O eixo de garantia de renda tratou-se de transferências monetárias para alívio imediato da situação de extrema pobreza e pôde ser resumido nos seguintes instrumentos: Programa Bolsa Família; Brasil Carinhoso e Benefício de Prestação Continuada de Assistência Social. O eixo de acesso a serviços orientou-se para o provimento ou ampliação de serviços e ações de cidadania e bem-estar social e resumiu-se nos Centros de Referência de Assistência Social (CRAS); Centros de Referência Especializada de Assistência Social (CREAS); Centros de Referência para População em Situação de Rua (Centros POP); Unidades Básicas de Saúde; e o Programa Mais Educação. Por fim, o eixo de inclusão produtiva buscou ofertar oportunidades de qualificação, ocupação e renda. Para a área urbana reuniu o Programa Nacional de Acesso ao Ensino Técnico e Emprego (Pronatec Brasil Sem Miséria) e o Programa Nacional de Promoção do Acesso ao Mundo do Trabalho (Acessuas Trabalho). Para a área rural contou com o Programa Nacional de Assistência Técnica e Extensão Rural (ATER); Programa de Fomento a Atividades Produtivas Rurais (Programa Fomento); Programa Água para Todos; Programa de Aquisição de Alimentos (PAA); Programa Nacional de Alimentação Escolar (PNAE); e, para a região norte, além dos já citados, também contou com o Programa Bolsa Verde.

Neste trabalho focaliza-se apenas nas ações do Plano que estiveram direcionadas ao rural e que se referiu especificamente à inclusão produtiva rural, observando a articulação de dois dos seus instrumentos: a assistência técnica e extensão rural e o Programa Fomento, no que concerniu especialmente às primeiras atividades de implementação, em 2011, 2012 e 2013.

Para completar a exposição dos elementos iniciais que introduzem a temática, é importante mencionar o Decreto 7.644, de 16 de dezembro de 2011, que regulamentou o Programa Fomento e estabeleceu o valor de $R \$ 2.400,00$ (dois mil e quatrocentos reais) para cada uma das famílias acompanhadas no âmbito do BSMRural. $O$ decreto definiu ainda que tal recurso seria repassado às famílias para a execução de um projeto produtivo e que este deveria ser acompanhado por um técnico do serviço de assistência técnica e extensão rural. A execução do Programa Fomento acoplou-se à assistência técnica e extensão rural e a sua implementação se deu por meio de uma rede de atores, desde a escala nacional até a local, e interligou ministérios, entidades de ATER governamentais e não governamentais,

\footnotetext{
${ }^{6}$ Rede sociotécnica é entendida, neste trabalho, nos termos de Bruno Latour (1994; 2003). Tal discussão tem sua gênese na proposição por simetria metodológica, quando em seus estudos reconhece agência a humanos e também a não humanos, que de meros objetos na teoria sociológica se tornam, nesta abordagem, mediadores, isto é, "atores dotados da capacidade de traduzir aquilo que transportam" (LATOUR, 1994, p. 79). Humanos e não humanos são atores em uma rede, denominada por Latour (2003) de rede sociotécnica. Se, por um lado, é pela implementação que se apreende os sistemas locais de ação pública, por outro, é bem provável que - ao analisar como os atores implementam -se compreenda que tais sistemas sejam dinamizados pelas redes existentes, redes estas compostas de atores múltiplos, nos termos de Latour.
} 
agricultores, territórios, extensionistas, colaboradores, e instituições parceiras. Diante disso, as seções seguintes buscam evidenciar as dimensões mobilizadas no processo de implementação do BSM-Rural e averiguar em que medida a dimensão da tradução e apropriação, do público, da mobilização dos atores, do tempo e lugar explicam a territorialização da ação pública no norte do estado de Minas Gerais cujo eixo, neste trabalho, é o da justaposição entre sistema local de ação pública e rede sociotécnica.

Este trabalho está organizado em cinco seções a contar desta Introdução. A segunda seção apresenta e discute a perspectiva de Lascoumes e Le Galès; a seguinte expõe o BSM-Rural; a quarta dedica-se à análise da implementação do BSM-Rural e a justaposição entre sistema local de ação pública e rede sociotécnica; e, por fim, serão apresentadas algumas considerações finais.

\section{A SOCIOLOGIA DA AÇÃO PÚBLICA E A IMPLEMENTAÇÃO}

É difícil identificar com precisão o ponto de partida das políticas públicas. Genericamente, a criação de formas institucionalizadas de poder político teve como consequências a criação de impostos, a formação das cidades, o abastecimento de produtos de primeira necessidade, o controle da população. (LASCOUMES; LE GALĖS, 2012). De modo geral, a estabilização das formas de governo é decorrente do conjunto de ações para dirigir e regular as sociedades. Essencialmente, as análises das políticas públicas advêm das sociedades nacionais e industriais que seguiram a trajetória da modernidade ocidental e foram dirigidas por um modelo político específico, o Estado.

Desde sua origem, a segunda metade do século $X X$, a análise das políticas públicas é permeada por uma tensão entre a perspectiva política e a sociológica. A perspectiva política de análise é concebida à luz da ciência política e atribui um papel preponderante ao Estado na condução da sociedade. Sob esta perspectiva origina-se a racionalidade top down. A perspectiva sociológica se interessa particularmente pela transformação, pelos grupos de interesse e entende os movimentos sociais como atores poderosos na transformação das políticas. Para Lascoumes e Le Galès (2012)essa perspectiva trata-se de uma observação da ação coletiva que estuda as organizações e as redes públicas e privadas e privilegia o raciocínio bottomup. "Sem que haja necessidade de reificar tais categorias, as expressões política pública e ação pública podem resumir essas duas perspectivas" (LASCOUMES; LE GALÈS, 2012, p. 49). ${ }^{7}$

A sociologia da ação pública tem mobilizado a sociologia do direito para compreender a produção e difusão de normas; tem buscado inspiração nas trajetórias e hábitos dos altos funcionários públicos, na formação do campo de intervenção dominantes/dominados - dos estudos de Pierre Bourdieu; e tem se interessado pela produção de categorias estatísticas, manifestação de problemas e das representações do mundo social. É ainda uma sociologia política que tem se

\footnotetext{
7 A partir dos anos 1970, os primeiros estudos sociológicos inverteram o olhar sobre o Estado e desenvolveram abordagens focadas na execução das políticas públicas. Nos Estados Unidos, em 1973, Pressaman e Wildavsky publicaram Implementation. Na França, Padioleau publicou l'Étatauconcret, em 1982, e alguns anos depois Jobert e Muller publicaram o l'Étatenaction, em 1987. Trataram-se das primeiras análises que partem dos executores e beneficiários dos programas públicos para compreender as dinâmicas da ação pública. Tais estudos encerram consideravelmente um ciclo de pesquisas que se concentraram na leitura de fracassos e limites das políticas públicas para observar os processos de implementação (miseenoeuvre). Configurou-se, portanto, a ação pública como "um espaço sociopolítico construído tanto por técnicas e instrumentos quanto por finalidades, conteúdos e projetos” (LASCOUMES; LE GALĖS, 2005, p. 21).
} 
interessado pelos conflitos, pelas regulações sociais e políticas; tem enfatizado as ações dos atores, suas interações e os sentidos que eles dão no espaço e tempo; tem considerado as instituições, as normas, as representações coletivas - estando bem próxima do modelo dos "três is", de Hall (1997), isto é, da abordagem de análise que considera "os interesses, as ideias e as instituições"; e, por fim, tem buscado na sociologia das ciências e das técnicas o aporte teórico sobre tecnologias e ferramentas de gestão. ${ }^{8}$

\subsection{OS SISTEMAS LOCAIS DE AÇÃO PÚBLICA E SUA APREENSÃO PELA IMPLEMENTAÇÃO}

Segundo Lascoumes e Le Galès a análise da implementação se origina da mudança de olhar sobre a intervenção do Estado, isto é, deixa-se de se analisar os fracassos e os limites dos programas e passa-se a buscar extrair leis gerais sobre os processos de ação pública. Os estudos passaram a identificar aquilo que determina a dinâmica de uma política pública mesmo que o objetivo não tenha sido atingido em excelência. Para os autores, a questão sociológica que está no centro do estudo da implementação é a produção de sistemas locais de ação pública e afirmam eles: "a implementação de uma política pública esforça-se para estabelecer ordens mais ou menos harmônicas entre os elementos programados e os discricionários" (LASCOUMES; LE GALÈS, 2012, p.81). Entre o que é pensado na formulação, na escolha da ferramenta e da técnica - elementos programados - e os ajustes, aqueles espaços abertos que permitem que os atores locais implementadores das políticas possam ajustar os procedimentos em distintas formas de fazer - elementos discricionários. Tais ordens nascem do fato de que os atores implementadores respeitam e partilham pressões, percebem condições, estabelecem alternativas e formulam compromissos (LASCOUMES; LE GALĖS, 2012; PADIOLEAU, 1982).

A análise da implementação, portanto, deve mostrar as formas e os impactos nas ordens locais, somente assim ela poderá descrever as transformações que a ação pública se propõe a introduzir. Há de se considerar, sobretudo, que programas e projetos governamentais são portadores de ambiguidades, com objetivos frequentemente vaporosos, com proteção de interesses e contradições, com ferramentas e técnicas imprevisíveis e que geralmente deixam a desejar na repartição das competências. Nesse sentido, para apreender as formas e os impactos da ação pública na ordem local os autores se reportam à dimensão da tradução e da apropriação por estas se mostrarem porta de entrada para a compreensão de como os atores implementadores constroem interpretações, se mobilizam no território e julgam prioritário em determinado momento.

O espaço da tradução e da apropriação é vasto e pouco estruturado, ele dá margem aos jogos de poder organizacionais internos às instituições e organizações. Por outro lado, esta dimensão se realiza também em interação com outras organizações envolvidas, e sob a pressão do contexto político local. Segundo Lascoumes e Le Galès, falar em execução de programas é considerar uma fórmula para designar um conjunto de atividades heterogêneas, cognitivas e normativas que, por sua vez, combinam dinâmicas internas (rotinas, modos habituais de agir) e um

\footnotetext{
${ }^{8}$ A compreensão do processo de implementação de políticas públicas vem ganhando reforços analíticos, com escolas nos Estados Unidos, França e Grã-Bretanha. Na França, por exemplo, a racionalização da ação pública que se desenvolveu a partir dos anos 1960 permitiu um triplo deslocamento das análises: a) em direção as atividades concretas de apropriação das políticas públicas pelos atores; b) de inverter a relação centro-periferia em benefício da periferia, assegurando assim um lugar central aos operadores da implementação; c) de romper com o mito da ação pública desinteressada.
} 
conjunto de negociações externas (desafios locais), que estão sob o que os autores chamam de regras de aplicação. As regras de aplicação são de três tipos: as normas de interpretação - "que dão significado operatório a enunciados abstratos"; normas de negociação - "que enquadram interações entre parceiros dos programas públicos e seus destinatários"; normas de resolução de conflitos - "que preveem as violações e estabelecem formas de solução de litígios" (LASCOUMES; LE GALĖS, 2012, p.84).

O destinatário, a dimensão do público beneficiário da política pública, também é estruturante na compreensão das formas e impactos na ordem local, ora auxilia na análise da produção dos sistemas locais de ação pública. Cada política pública contém imposições, ou seja, aquelas condições a serem preenchidas por um determinado indivíduo para ele ser enquadrado no programa. Há, no mínimo, dois níveis para se analisar as imposições: o primeiro está relacionado à dimensão das traduções e diz respeito ao modo como o ator implementador reconhece o público. O segundo é o das exigências administrativas embutidas nas ferramentas e técnicas do programa. Geralmente essas exigências criam "dificuldades", não permitindo que o programa chegue massivamente ao público, deixando fora parte dos indivíduos que teriam perfil.

A mobilização dos atores só pode ser compreendida mediante uma contextualização precisa e uma análise dos múltiplos desafios locais, sejam eles de uma organização, de um território ou das redes deste território. A contextualização deve ser feita no presente, observando que um programa público sempre está vinculado a outro e os atores atuam em interação frente aos diferentes desafios. Os quadros administrativos das instituições também são importantes para dar concretude à execução dos programas, eles devem ser observados, assim como as identidades de ação a nível territorial. Lascoumes e Le Galès completam: "é difícil compreender as performances dos atores locais, isto é, a forma como eles dão significado e se apropriam desta ou daquela parte do programa sem conhecer a história de suas interações, os compromissos de trabalho, bem como as novas alianças" (LASCOUMES; LE GALĖS, 2012, p.86). Em razão disto, é preciso fazer uma cartografia do estado em que se encontram as relações de forças locais para compreender os atores e os recursos que eles dispõem. Uma caracterização das configurações locais permitirá o conhecimento dos sistemas locais de ação concreta, das relações de poder, dos recursos e das obrigações, dos quadros cognitivos e das rotinas da ação pública territorializada.

Por fim, o tempo e o lugar da execução dos programas devem ser considerados como espaços de ajustamento, período de negociação de interesses, onde as controvérsias são momentos de confrontação, mas também momentos de aprendizado. A atividade de implementação pode ser um momento de transformação na definição do problema, na posição e reivindicação dos atores envolvidos e nas formas de operar ao que se refere à mudança de critérios e procedimentos. Na dimensão do tempo e lugar podem ser observadas as apropriações dispersas e como elas são seguidas de momentos de redefinição, discussão e reorientação. Mas, o mais interessante é compreender o que as tornam possíveis em um vasto espaço de interações criado pela implementação. De um território a outro as configurações são muito diferentes, e os espaços de ação construídos pelas relações práticas dos atores implementadores, onde não obedecem aos recortes políticos-administrativos. Estes "espaços de ação construídos" são inventados pelas redes do território para atender as especificidades das dinâmicas locais e "fugir" da burocracia da compartimentação. 


\section{O BSM-RURAL: UMA BREVE APRESENTAÇÃO}

Em 2011, Dilma Rousseff chegou à Presidência da República com a proposta de continuidade das ações de superação da pobreza expressa no que ela chamou de erradicação da pobreza extrema. O Plano Brasil Sem Miséria, instituído pelo Decreto Presidencial 7.492, em junho desse mesmo ano, foi pensado com o objetivo de superar a situação de extrema pobreza da população em todo o território nacional por meio da integração e articulação de políticas, programas e ações ${ }^{9}$. Conforme discurso da sua Ministra de Estado, Tereza Campello, em ato comemorativo dos dez anos do Programa Bolsa Família, em 2013, o Plano Brasil Sem Miséria incorporou as ações de combate à pobreza, existentes desde 2003, e as qualificou. Dado o arranjo e articulação de políticas, programas e ações promovidos pelo Plano Brasil Sem Miséria, analisa-se neste trabalho somente as atividades desencadeadas pelo Plano que estão relacionadas ao Programa Fomento e a assistência técnica e extensão rural.

Nesse sentido, cabe mencionar que a estrutura organizacional do BSMRural referente ao Programa Fomento comportou um Grupo Gestor - formado pelo Ministério do Desenvolvimento Social (MDS); Ministério do Desenvolvimento Agrário $(\mathrm{MDA})^{10}$; Ministério da Fazenda; Ministério do Planejamento, Orçamento e Gestão; e Casa Civil. O Decreto 7.644 de Dezembro de 2011 - que regulamentou o Programa de Fomento - definiu as competências do Grupo Gestor e responsabilizou o MDA e o MDS pela sua operacionalização. Observa-se que, ao que se referiu às ações de inclusão produtiva rural, mencionadas na Introdução deste trabalho, o Programa Fomento foi $o$ instrumento criado especificamente para o BSM-Rural e teve gestão compartilhada entre as pastas ministeriais citadas. Para tanto, à época, o MDS disponibilizou o Cadastro Único para Programas Sociais do Governo Federal (Cadúnico) e o recurso de dois mil e quatrocentos reais por projeto de estruturação produtiva. O MDA disponibilizou os dados da Declaração de Aptidão ao Pronaf (DAP) e o recurso para assistência técnica - via as Chamadas Públicas de Contração de Serviços de ATER (Chamada Pública) (conferir (cf.) figura 1).

O público do BSM-Rural elegível ao recurso de $\mathrm{R} \$ 2.400,00$ foram agricultores/as familiares, de acordo com a Lei da Agricultura Familiar, com renda per capita mensal abaixo de setenta reais, que estivessem cadastrados no Cadúnico e recebessem Bolsa Família. ${ }^{11}$ Os beneficiários deveriam ainda possuir DAP na categoria B, ou seja, DAP B (agricultores elegíveis ao Pronaf B), cuja renda era de até setenta reais per capita mês. O Decreto 7.644 assegurou ainda que era de competência do MDA articular a emissão de DAP para integrantes das famílias que se enquadrassem no Programa Fomento e ainda não possuíssem o documento.

A operacionalização do BSM-Rural se deu, inicialmente, da seguinte maneira: o MDA lançava o edital denominado Chamada Pública para contração de serviços de assistência técnica e extensão rural para atuação no BSM-Rural. Neste documento constava a área de abrangência, o número de famílias, o número de atividades a serem realizadas e o valor total do recurso disponibilizado. As empresas governamentais de ATER, assim como as organizações não governamentais propunham projeto para atuação (concorriam ao edital). A instituição selecionada

\footnotetext{
${ }^{9}$ Em Outubro deste mesmo ano é instituída a Lei 12.512 que trata do programa de fomento para as atividades produtivas rurais, e em Dezembro esta Lei é regulamentada pelo Decreto 7.644.

${ }^{10}$ O Ministério do Desenvolvimento Agrário foi extinto pela Medida Provisória oㅡ 726 de 12 de maio de 2016 do Vice-presidente da República em exercício, Michel Temer, um dia depois da votação no Senado Federal que deu sequência ao impedimento da presidenta eleita Dilma Rousseff.

${ }^{11}$ Com o Decreto 8.232 de 2014, a renda per capita orientadora do Plano Brasil Sem Miséria passa para $\mathrm{R} \$ 77,00$.
} 
assinava um contrato de prestação de serviço com o MDA e tinha um tempo determinado para realização das atividades previstas.

Figura 1 - Organograma da rede do BSM-Rural.

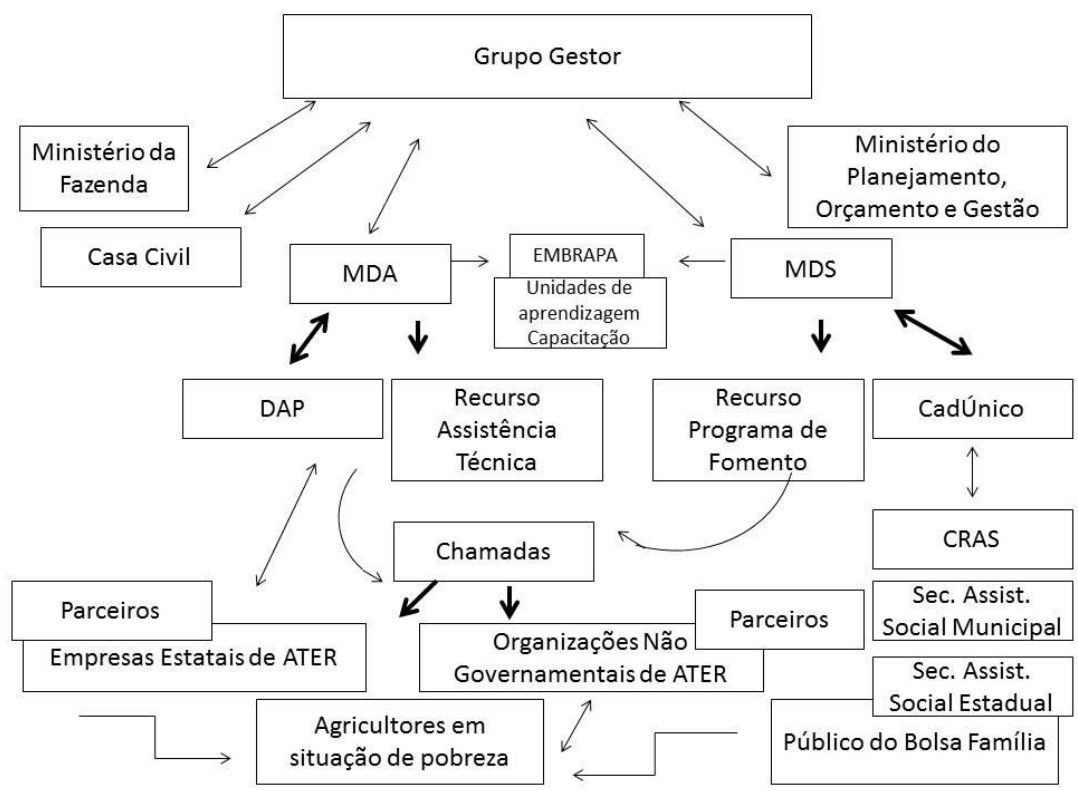

Fonte: elaborado pela autora, com base nos dados da pesquisa documental, novembro de 2014.

Dentre as atividades esteve a de elaboração de um projeto de estruturação produtiva que o técnico/colaborador de assistência técnica deveria elaborar juntamente com a família em situação de pobreza extrema. Para execução do projeto o MDS enviava para a família um valor em dinheiro, um recurso não reembolsável, no cartão do Programa Bolsa Família - após o ateste do técnico/colaborador de ATER. Este recurso começou a ser liberado, em 2011, em três parcelas, e em agosto de 2015 estava sendo liberado em duas ${ }^{12}$. Os projetos de estruturação produtiva, denominados também de projetos de inclusão produtiva, tiveram como objetivo gerar renda e promover a segurança alimentar e nutricional das famílias. O quadro 1 abaixo, apresenta os programas articulados no eixo de inclusão produtiva rural do Plano Brasil Sem Miséria, ao que se referiu às ações para o rural. Os grifos destacam os programas eleitos à análise neste trabalho:

\footnotetext{
12 Ressalto que este texto foi escrito em novembro de 2014, atualizado em agosto de 2015, e revisado em setembro de 2017. Portanto, as informações nele contidas referem-se à pesquisa documental de 2012 e a pesquisa de campo de 2013.
} 
Quadro 1 - Programas direcionados a superação da pobreza rural

\begin{tabular}{|c|c|c|}
\hline Responsável & Programas do Eixo Inclusão Produtiva Rural & Ano de criação \\
\hline MI/MDS & Programa Água para Todos & $2003 / 2007^{*}$ \\
\hline MDS/MDA & Programa de Aquisição de Alimentos (PAA) & 2003 \\
\hline MDS & Programa de Alimentação Escolar (PNAE) & $1955 / 2009^{* *}$ \\
\hline MMA/MDS & Programa Bolsa Verde & 2011 \\
\hline MDA & Programa de Assistência Técnica e Extensão Rural & 2003 \\
\hline MDS/MDA & Programa de Fomento a Atividades Produtivas & 2011 \\
\hline
\end{tabular}

Fonte: elaborado pela autora, com base em MDS (2015), agosto de 2015.

* Cisternas para consumo, 2003, para produção criada em 2007;

** Programa criação em 1955, e estendido para toda a rede pública em 2009.

Este trabalho dedica-se especialmente em analisar como a assistência técnica e extensão rural, no norte do estado de Minas Gerais, iniciou o trabalho de implementação do Programa Fomento no Território da Cidadania Serra Geral, uma vez que a implementação mobilizou, no âmbito do território, distintas redes de atores sociais. Para facilitar a compreensão, faz-se necessário mencionar que as Chamadas Públicas, nessa época, eram lançadas para Territórios da Cidadania, e somente as instituições de ATER governamental e não governamental - atuantes no território - podiam concorrer à Chamada, ora atuar com os agricultores/as, no caso, em situação de extrema pobreza. No norte do estado de Minas Gerais, a Chamada Pública foi lançada para o Território da Cidadania Serra Geral (cf. figura 2), juntamente com mais dois territórios, o Território do Velho Chico e o de Irecê, ambos na Bahia. Essa Chamada Pública, lançada para três territórios da cidadania, em 2011, foi a primeira Chamada para atuação com o Plano Brasil Sem Miséria Rural, no Brasil.

Figura 2 - Localização do Território da Cidadania Serra Geral em Minas Gerais

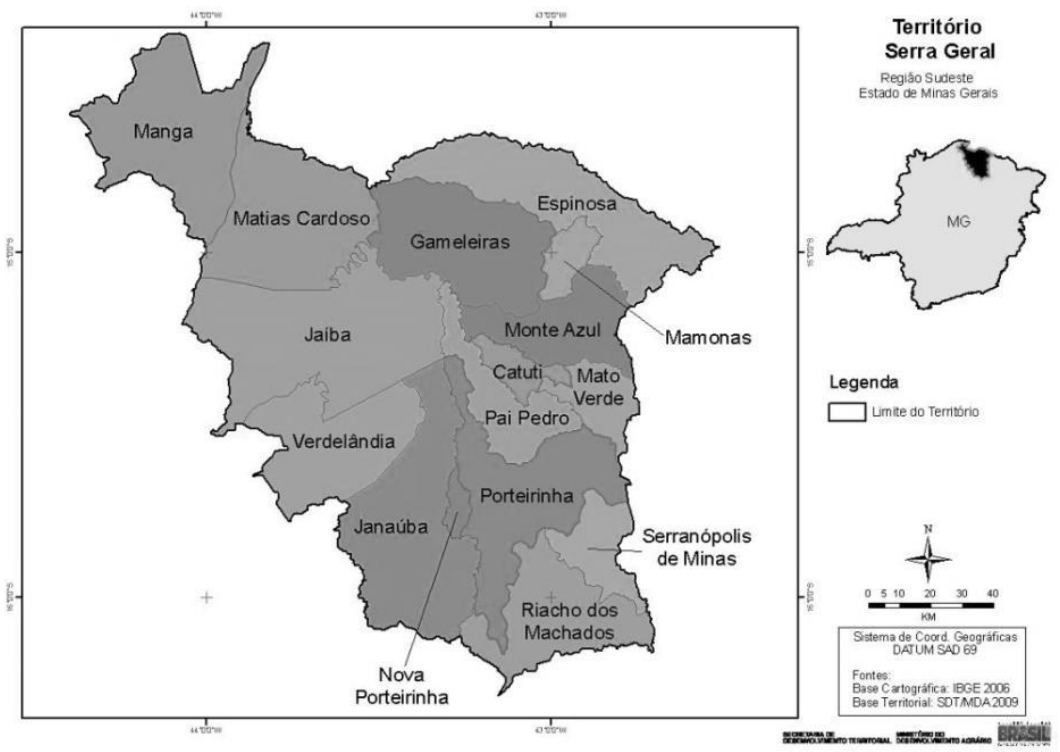

Fonte: SDT/MDA, 2013. 
Conforme figura 2, o Território Serra Geral é composto por 16 municípios sendo eles: Catuti, Espinosa, Gameleiras, Jaíba, Janaúba, Mamonas, Manga, Matias Cardoso, Mato Verde, Monte Azul, Nova Porteirinha, Pai Pedro, Porteirinha, Riacho dos Machados, Serranópolis de Minas e Verdelândia. De acordo como Altas de Desenvolvimento Humano - PNUD 2010, o território possui uma população de 285.625 habitantes, desses 180.437 estão em áreas urbanas e 105.188 habitam áreas rurais. Os municípios do referido território se caracterizam por um baixo Índice de Desenvolvimento Humano Municipal (IDHM) que variam de 0,584 a 0,696, respectivamente, Verdelândia e Janaúba, sendo este último o mais populoso, com 66.000 habitantes, e o outro o menor, com 4.000 habitantes.

As atividades industriais são pouco expressivas no território, a concentração em nível de região é em Montes Claros, cidade polo do norte de Minas Gerais, que fica fora do Território Serra Geral, a uma distância de $130 \mathrm{~km}$ de Janaúba. A economia no Território Serra Geral é diversificada, embora haja concentração de terras e uma presente atividade de pecuária intensiva concentrada em latifúndios. O território concentra um dos polos de floresta plantada (eucalipto e pinus) do estado de Minas Gerais, constituído por ações governamentais direcionadas à região nas décadas de 1970/80. Juntamente com tal projeto de floresta plantada somaram-se projetos de agricultura irrigada, de pecuária intensiva, mineração, monocultivo de algodão associados à instalação de um parque agroindustrial têxtil, indústria de cimento e cerâmica que, segundo estudos, não promoveram o desenvolvimento nos termos objetivados para a região, ao contrário, contribuíram para o agravamento das desigualdades sociais, e aprofundando de situações de pobreza (NOGUEIRA, 2009; DAYRELL, 1998; AMADO, 1995; MATAMACHADO, 1991; ANASTASIA, 1989).

O território concentra uma diversidade de identidades territoriais que expressa, por sua vez, a diversidade cultural e de modos de apropriação dos recursos naturais no território, ora exprimem também uma diversidade produtiva e econômica, de base familiar, na região. Proveniente de identidades como a de Vazanteiro, Geraizeiro, Caatingueiro, Quilombola, Indígena e Agricultor Familiar, os povos e comunidades tradicionais do norte de Minas Gerais produzem e processam alimento, tem casa de farinha, extraem frutos do cerrado, raízes e plantas, criam animais, trabalham com hortaliças (em regiões onde o acesso à água é facilitado), pescam - quando se tratam de comunidades ribeirinhas (o Rio São Francisco atravessa o norte de Minas). Enfim, há uma dinâmica econômica, social e política territorializada - entretanto, frágil - que vinha sendo fortalecida por meio das redes de organizações da sociedade civil, sindicatos, Pastoral da Terra, movimentos sociais e políticas públicas. Estes poucos dados de contextualização do território subsidiam minimante e ajudam a perceber a dinâmica e a necessidade do território para com programas e políticas públicas que conciliem o fortalecimento da agricultura familiar face ao enfrentamento da pobreza.

Assim, é nesse território que, em 2011, o BSM-Rural começou a ser implementado por meio da Chamada Pública de ATER. Os atores implementadores em questão, ou seja, as instituições que foram selecionadas e contratadas para realizar a assistência técnica e extensão rural foram a Emater Minas Gerais (Emater/MG) e Centro de Agricultura Alternativa do Norte de Minas Gerais (CAA/NM). Estas duas instituições concorreram e ganharam um lote de municípios cada uma, com 800 beneficiários em cada lote. ${ }^{13}$

\footnotetext{
${ }^{13}$ O Território Serra Geral foi dividido em dois lotes, excluindo três municípios. O primeiro, lote 9, com sete municípios, e o segundo, lote 10, com seis municípios. Respectivamente: Catuti, Espinosa, Mamonas, Mato
} 


\section{OS SISTEMAS LOCAIS E AS REDES SOCIOTÉCNICAS: A JUSTAPOSIÇÃO}

O início da implementação do BSM-Rural no território se deu com a chegada da lista de beneficiários. O Ministério do Desenvolvimento Agrário enviou à Emater/MG e ao CAA/NM uma lista com o nome de ao menos um dos membros da família que seria acompanhada pela ATER, com cadastro de pessoa física (CPF) e ordem prioritária de acompanhamento. Esta ordem de prioridade foi baseada na renda da família e organizada da menor para a maior renda dentro do roll de famílias em situação de extrema pobreza em cada um dos lotes da Chamada Pública. Isso porque o número de beneficiários contidos na lista era maior do que o número de beneficiários que cada instituição tinha por obrigação contratual acompanhar. Esse formato fez com que cada instituição escolhesse, da lista, as famílias com quem iriam atuar. Segundo a literatura da sociologia da ação pública, essa manobra pode ser lida como àquelas condições de ajustes à regra geral embutidas nas ferramentas, de forma intencional ou não, e que são percebidas pelos atores implementadores ao longo do curso da implementação da política pública.

Dessa forma, analisa-se também que a lista de beneficiários excedeu o número para que justamente as instituições compusessem o universo das famílias que acompanhariam. Por um lado, isso possibilitou que as instituições tivessem uma pequena margem de ajuste, uma brecha que, grosso modo, favoreceu formas de fazer (por mais impositiva que a lista tenha sido no primeiro momento). Nesse contexto, foi ficando evidente que as formas de fazer a implementação do Plano distinguiram-se na proporção em que os atores implementadores e parceiros não eram os mesmo. O CAA/NM, por exemplo, optou por contemplar parte significativa das comunidades rurais de cada um dos municípios de atuação, ampliando o alcance geográfico da política pública dentro do seu lote de atuação. A Emater/MG preferiu concentrar a atuação de modo a contemplar o maior número possível de beneficiários de uma mesma localidade considerando, dentre outras coisas, a logística. Ambas as estratégias foram reavaliadas pelas instituições nas edições seguintes.

Nesta seção, para compreender se os sistemas locais de ação pública estão justapostos às redes sociotécnicas existentes no território Serra Geral optouse por partir da ferramenta lista de beneficiários do Plano Brasil Sem Miséria e mapear como os atores implementadores foram acoplando os parceiros, e quais parceiros, na implementação do Plano no Território da Cidadania Serra Geral, no norte do estado de Minas Gerais, e como foram traduzindo os elementos programados (àqueles que chegam com a política pública) e construindo os discricionários (àqueles que são elaborados no local), nas suas respectivas redes de atuação. De acordo com Lascoumes e Le Galès (2012), os sistemas locais são apreendidos a partir da análise do processo de implementação e compreendê-la é lançar-se a entender como são estabelecidas ordens mais ou menos harmônicas entre os elementos.

Para tanto, discute-se nas seções seguintes a constituição da lista dos beneficiários, o estabelecimento das parcerias e os modos habituais de agir, a busca ativa em comunidades quilombolas e jogo por detrás do reconhecimento do público da política pública, muitas vezes ocultados pelas exigências administrativas. Partese, sobretudo, do entendimento de que em uma rede sociotécnica, além de atores

Verde, Monte Azul, Pai Pedro, Serranópolis de Minas, com a Emater/MG; Jaíba, Janaúba, Manga, Matias Cardoso, Porteirinha, Verdelândia, com o CAA/NM. 
humanos, os não humanos (por exemplo: as técnicas, as ferramentas, os bancos de dados, a lista de beneficiários, e etc.) também são dotados de capacidade de traduzir aquilo que transportam, e neste movimento se tornam mediadores (LATOUR, 1994, p. 79). Para o caso do norte do estado de Minas Gerais, pode não ser exagero ou mera retórica, perguntar-se em que medida o rio São Francisco, o Gerais, as políticas públicas materializadas em cisternas, em ferramentas que devem ser interpretadas, os projetos e os documentos exigidos exercem papéis ativos quando acionados no território, uma vez que é a apropriação e a tradução que se faz destes que são, a princípio, objetos ou entes da natureza, que expressarão modos e identidades de ação.

\subsection{A LISTA DE BENEFICIÁRIOS E A CONFLUÊNCIA DE BANCOS DE DADOS}

A lista de beneficiários foi gerada pelo MDA e pelo MDS, da seguinte forma: o primeiro consultou o banco de dados da DAP filtrando, por município, as famílias com renda per capita/mês abaixo de setenta reais e, o segundo, utilizou o banco de dados do Cadúnico, também pesquisando por famílias com renda de até setenta reais. Cada pasta ministerial, portanto, obteve uma lista de famílias em situação de extrema pobreza, todavia, era preciso avançar, e o desafio era realizar o cruzamento desses bancos de dados de modo a se obter uma única listagem. ${ }^{14} \mathrm{O}$ banco de dados da DAP enquanto um sistema de gestão de informação que foi criado para a emissão da declaração de aptidão ao Programa de Fortalecimento da Agricultura Familiar (Pronaf), tendo atuado também como uma ferramenta de "autorização" à demanda de crédito rural, ao ser cruzado com o Cadúnico, que também cumpriu a função de sistema de gestão de informação e registrou as famílias que demandaram o Programa Bolsa Família - mas não somente porque se tratou de um registro social das famílias que demandaram, sobretudo, assistência social no Brasil -, gerou uma lista das famílias em situação de pobreza extrema. Este dois bancos de dados foram os principais sistemas que acondicionaram informações no MDA e no $\mathrm{MDS}^{15}$, respectivamente, com semelhanças e diferenças: o primeiro dizia quem eram os agricultores familiares (e também quem eram os agricultores familiares pobres), o segundo dizia quem eram os pobres (rurais e urbanos) - público da política de assistência social. Ambos eram declaratórios, com algumas ressalvas: no primeiro o agricultor precisava convencer o mediador que $50 \%$ da sua renda era proveniente de atividades rurais (em algumas situações era preciso comprovar), no segundo caso, o demandante precisava convencer de que era pobre, isto é, que tinha baixa renda.

As exigências administrativas - como a solicitação de documento de terra e/ou contrato de parceria e uso do solo, nota de produtor, ou até mesmo a demanda de informações como, por exemplo, os locais de comercialização - eram comuns e presentes rotineiramente nas instituições que emitiram/emitem a DAP. Solicitar documentos trata-se de um procedimento, de uma regra de aplicação interna e internalizada que, de alguma maneira, reflete o reconhecimento institucional, ou não, do que é ser agricultor, do que é ser, ou não, pobre. Em relação ao Cadúnico, a estratégia de reconhecimento era um pouco diferente, havia um processo de

\footnotetext{
${ }^{14}$ O MDS cria um sistema de leitura dos dados, capaz de reunir informações desses dois bancos de dados e gerar listagem.

${ }^{15}$ Aqui menciona-se que "foram os principais sistemas" (tempo verbal passado), primeiramente, porque este trabalho expõe e analisa dados de 2012 e 2013, sobre uma política pública em particular e, em segundo lugar, com o desmonte das políticas públicas da agricultura familiar e de proteção social, acelerado no Brasil desde maio de 2016, não se sabe ao certo em que medida esses sistemas de informação e de cadastro ainda estão vigentes.
} 
avaliação e preenchimento do sistema, composto por uma série de perguntas detalhadas (para emissão de DAP também havia sistema e perguntas), o diferencial estava no nível das exigências administrativas de cada um desses sistemas mediados por sujeitos, funcionários públicos.

Outra diferença entre eles estava na instituição cadastradora, por exemplo, na época, a DAP era emitida pela empresa governamental de ATER (majoritariamente) e o cadastro do Cadúnico feito nas Secretarias de Assistência Social dos municípios. A princípio havia uma paridade em termos de capilaridade destas instituições nos municípios brasileiros. Todavia, é importante considerar mais uma regra de aplicação: enquanto no primeiro caso o técnico de ATER precisava ser convencido de que o demandante era agricultor familiar, no segundo, o funcionário da secretaria municipal responsável pelo cadastro deveria aceitar a auto declaração do demandante.

O sistema de gestão da informação do MDA teve como objetivo a emissão do documento DAP, por sua vez, o Cadúnico era um cadastro de localização da pobreza. Até então, a DAP, cada vez mais vinha sendo utilizada para definir o público das demais políticas públicas do MDA, extrapolando o seu uso para fins de demanda de crédito Pronaf e, por sua vez, vinha promovendo um processo de exclusão das camadas mais pobres do campo, como é o caso das comunidades vazanteiras do norte de Minas Gerais ${ }^{16}$, para citar um exemplo. Por mais que os dois sistemas de gestão tenham sido substanciosos, com conteúdo diversificado e informações capazes de contextualizar a situação das famílias, ambos foram pouco explorados para composição da lista (inicialmente). Por exemplo: era possível retirar do sistema de informação da DAP a informação sobre a situação fundiária dos agricultores - se eram proprietários, parceiros, meeiros e etc., que, de certo modo, caracterizava e mostrava o perfil da família em relação ao acesso à terra - elemento chave no enfrentamento da pobreza e desenvolvimento territorial -, entretanto, pouco considerado no BSM-Rural de modo geral.

Muito embora com limitações iniciais, o Cadúnico foi se constituindo em uma das melhores ferramentas de caracterização e busca ativa do cidadão em situação de pobreza e pobreza extrema que já existiu no âmbito do Governo Federal, justamente pela sua cobertura nacional, atualização bianual das informações e conjunto de informações que oferecia. Era possível encontrar informações que davam conta de uma análise com enfoque multidimensional da pobreza, principalmente, dados referentes ao acesso à água e políticas públicas que, igualmente, foram despriorizados a favor do fator renda. Diante disto, DAP e Cadúnico imprimiram o público beneficiário a partir da imposição estrutural do instrumento da ação pública, isto é, ao dizer quem é o agricultor em situação de pobreza a partir da renda declarada e da efetivação das exigências administrativas.

Obviamente que, por se tratar de uma política pública em construção, o Plano Brasil Sem Miséria foi sofrendo modificações e amadurecimentos ao longo do processo de implementação, e as instituições de ATER governamental e não governamental tiveram papel central nos ajustes do instrumento e das ferramentas estabelecendo, principalmente, alternativas de ajustes às ferramentas.

\footnotetext{
${ }^{16}$ Os vazanteiros das margens do rio São Francisco, em Minas Gerais, em sua maioria, ficaram fora das atividades da primeira edição do PBSM. Segundo informações, a lógica do uso do solo, comuns para comunidades vazanteiras (migração das ilhas para a margem do rio e vice versa) dificultava o reconhecimento desta categoria social com agricultor familiar perante o órgão emissor de DAP. Não tendo tal documento, as famílias não foram visualizadas no cruzamento de sistemas - Cadúnico e DAP, ou seja, elas não existem enquanto pobres que demandam instrumentos da ação pública.
} 


\subsection{O ESTABELECIMENTO DE PARCERIAS E O MODO HABITUAL DE AGIR}

Com base na pesquisa documental realizada em 2012, que teve como fonte os editais das Chamadas Públicas e produtos de consultoria do PNUD/MDA e, principalmente, com base na pesquisa de campo realizada no norte do estado de Minas Gerais, em 2013, que reuniu por meio de entrevista, dados qualitativos acerca do processo de implementação do Plano Brasil Sem Miséria Rural no Território da Cidadania Serra Geral, apresenta-se a seguir como a lista de beneficiários, gerada por meio da articulação de pastas ministeriais, foi apropriada e traduzida no âmbito local de modo distinto.

O CAA/NM, ao portar a lista de beneficiários, optou por discuti-la junto ao Sindicato dos Trabalhadores Rurais (STR) dos municípios do lote de atuação, em especial o STR de Porteirinha, assim como a discutiu com as lideranças comunitárias organizadas em associações e, também, com a Comissão Pastoral da Terra (CPT) - organização antiga e ativa no território. O debate em torno da lista gerou as primeiras percepções em torno do programa público e os primeiros encaminhamentos. Sobre as percepções iniciais: (i) observaram que os mais pobres do território não estavam com o nome na lista por não estarem no Cadúnico ou por não terem DAP; (ii) a ordem de prioridade de acompanhamento das famílias não se justificava; e (iii) o recorte de renda era insuficiente visto a situação semelhante que viviam as famílias. Em relação aos encaminhamentos, esses atores sociais envolvidos com a implementação do Plano foram (i) pautando tais constatações sem cada um dos espaços de formulação de políticas públicas que participavam e, devido às fragilidades identificadas optaram, sobretudo, pela decisão coletiva, isto é, (ii) contando com a opinião dos parceiros, sem deixar de considerar seu próprio modo de agir habitual, ou seja, o de incorporar famílias com quem já tinham algum trabalho. Essa opção caracterizou-se também como um modo de resolução de conflito, pois tinham uma vasta lista, com uma composição frágil, e tinham a opinião dos parceiros, conhecedores da realidade e protagonistas no território.

Por ser um Plano recente, de extrema importância no Governo Federal na época, a cautela em relação à lista também pôde ser observada do lado da Emater/MG. Depois de realizarem um checklist com a equipe interna, a instituição procurou os seus parceiros mais próximos e discutiu a lista com presidentes de associações de produtores e agricultores, e também em alguns sindicatos. $O$ objetivo era o de obter respaldo na escolha, queriam selecionar os mais pobres da lista de pobres utilizando o conhecimento interno das equipes e o dos parceiros. De imediato identificaram fragilidades da ferramenta-lista: (i) o recorte de renda não refletia a realidade, independentemente de a família ter renda de setenta ou de cento e quarenta reais a realidade de necessidades era a mesma; e(ii) que famílias em situação mais difícil, de pobreza extrema, ficaram fora da lista. Dessa maneira, optaram por utilizar o conhecimento que tinham acerca dos nomes listados, e valeram-se substancialmente de seu modo de agir habitual, ou seja, a partir do conhecimento acumulado acerca das atividades produtivas das famílias, o acesso ou não delas ao crédito Pronaf, e famílias com quem já tinham algum tipo de trabalho anterior.

\subsection{A ATUAÇÃO COM AS COMUNIDADES QUILOMBOLAS E A BUSCA ATIVA}

É extremamente relevante considerar que o CAA/NM e a Emater/MG também atuaram com a Chamada Pública específica de comunidades quilombolas e que, para este caso, não houve lista de beneficiários. As duas instituições tiveram que realizar uma busca ativa, isto é, ainda com a contribuição dos respectivos 
parceiros, e contando também com as associações quilombolas dos respectivos quilombos de atuação, a saber, Gorutuba e Poções, e o CRAS dos municípios em questão - listaram famílias elegíveis ao programa e, em um segundo momento, fizeram visitas às casas das famílias para confirmar ou não a seleção prévia. Para o quilombo do Gorutuba optaram por não selecionar famílias que tivessem renda de aposentadoria rural. Contudo, o critério renda foi um critério menor de modo geral, considerado, mas com menor peso. Consideraram o número de pessoas em uma unidade doméstica, visto que é comum em comunidades quilombolas várias famílias habitarem a mesma unidade. Nesse sentido, o CAA/NM pressionado pela realidade local estabeleceu alternativas e deu início a uma discussão interna à instituição e constitutiva de um posicionamento em relação ao termo 'unidade familiar de produção', utilizado na Chamada Pública, que entende uma propriedade igual a uma família.

Os fatores 'condições da habitação' e 'distância em relação ao centro urbano' também foram considerados. A busca ativa das famílias realizada pelo $\mathrm{CAA} / \mathrm{NM}$ mesclou as orientações da política pública com o que podemos denominar de normas de interpretação, que são as definições do perfil da família desenhadas a partir de elementos reais/locais, visíveis no território quilombola e escolhidas juntamente com os parceiros. Esse ponto, em especial, ilustra o que os autores da sociologia da ação pública chamam de ordens mais ou menos harmônicas entre os elementos programados e os discricionários, ou seja, na implementação há um esforço para estabelecer conexões entre o que vem pronto com a política pública e o que demanda ajuste no território.

Consequentemente, no Quilombo do Gorutuba, mais de setecentas famílias foram identificadas em situação de enquadramento ao programa. Todavia, o número máximo previsto para acompanhamento era o de quinhentas famílias. Desse total grande parte não era portadora de DAP e iniciou-se, assim, um longo e desgastante processo para emissão desse documento. Esse processo contou com articulações territoriais iniciadas pela instituição, organização das famílias e intervenções do MDA. A intervenção, em especial, pode ser lida a partir do que Lascoumes e Le Galès chamam de negociações externas às regras de aplicação, isto é, a regra existe só que por si só não se garante que seja aplicada, e é preciso intervenção externa. As famílias que não conseguiram a emissão, mesmo tendo perfil, não puderam participar das ações do BSM-Rural.

Para o Quilombo de Poções, a busca ativa pelas famílias considerou, primeiramente, os dados do Cadúnico extraído junto ao CRAS municipal, a opinião de presidentes de associações comunitárias localizadas dentro do quilombo, e o ser ou não portador de DAP também foi definidor, ou seja, ser ou não agricultor nos termos das exigências. Os desafios enfrentados no momento da identificação das famílias estiveram em torno também do que é ser ou não quilombola, e a Emater/MG contou com a contribuição das associações comunitárias e relatos de pessoas idosas da comunidade para sair do impasse. A lista de associados da associação quilombola também foi considerada. Por sua vez, havia receio institucional em beneficiar pessoas que não fossem 'realmente' quilombolas.

Assim, no Quilombo de Poções, duzentas e sessenta famílias foram identificadas, não atingindo o número máximo previsto em contrato, trezentas e vinte. Também foram realizadas visitas às famílias para averiguação do enquadramento, ou seja, em quais condições viviam e se eram agricultores familiares para possível emissão de DAP, caso necessário. Esta estratégia vinculase também a um modo de agir habitual da instituição. $\mathrm{E}$, de fato, várias famílias não tinham o documento, e o emissor - que nesse caso era também o implementador do Plano - ao averiguar que se tratavam de agricultores familiares, ou não, 
providenciavam, ou não, a emissão do documento. Novamente está em jogo, no processo de apropriação e tradução do instrumento, a configuração de normas de interpretação do BSM-Rural e regras de aplicação que extrapolam os elementos programados do Plano.

\subsection{O JOGO DO RECONHECIMENTO OCULTADO PELAS EXIGÊNCIAS ADMINISTRATIVAS: O PAPEL DOS PARCEIROS NAS TRADUÇÕES}

As ferramentas discutidas até então, lista de beneficiários, DAP e Cadúnico, são permeadas de condições que os indivíduos devem preencher para serem enquadrados nos programas públicos que utilizam essas ferramentas. Essas imposições estruturadoras provenientes das políticas públicas cujas quais tais ferramentas estão vinculadas podem ser interpretadas pela via da imposição de quem é o pobre rural e pelas exigências administrativas, ponto este que efetiva o primeiro. O quem é permite compreender como o público é reconhecido (em uma escala nacional) pela política pública, e pelos atores implementadores (na escala do território), e como estes reconhecimentos podem ser diferentes entre essas escalas; no que concerne a segunda imposição, das exigências, fica evidente como as ferramentas e as técnicas escolhidas constroem o público e também a fronteira entre os que ficam dentro e os que ficam fora.

Parceiros como professores, pesquisadores e estudantes da Unimontes de Janaúba e também da de Montes Claros foram acionados e em diferentes momentos: em um primeiro momento para tratar da temática da pobreza rural junto aos colaboradores do CAA/NM; e, em outro momento para compor o grupo de suporte tecnológico com a Embrapa. A participação da universidade foi importante também na defesa do ponto de vista tecnológico da organização. A Cooperativa Grande Sertão, parceira em outros projetos, disponibilizou o caminhão para distribuição das sementes que foram enviadas pela Embrapa para as famílias beneficiárias do Plano. Para o trabalho do CAA/NM também as associações comunitárias foram parceiros fundamentais, no papel das lideranças comunitárias que organizaram espaços físicos para as reuniões, convidaram as famílias para as agendas e se fizeram presentes na demanda de emissão de documentos. Da mesma forma no trabalho com as comunidades quilombolas, as associações foram centrais assim como a articulação com os sindicatos, o de Montes Azul, por exemplo, teve participação indispensável na emissão de DAP para essas comunidades.

Do modo semelhante, a Emater/MG incorporou parceiros nas agendas de implementação do BSM-Rural. Geralmente a Prefeitura é a principal parceira da instituição em praticamente todos os municípios, e também pela relação histórica destas com o governo do estado de Minas Gerais. Por meio delas processos de infraestruturas foram facilitados: as Secretarias de Assistência Social nos municípios do lote de atuação da Emater/MG disponibilizaram os dados e o conhecimento acerca da realidade social rural das famílias dos municípios, assim como contribuiu com transportes e espaços para atividades; agentes de saúde também contribuíram com informações sobre as famílias. A Emater/MG pôde contar ainda com o Conselho Municipal de Desenvolvimento Rural Sustentável (CMDRS) ao que se refere à divulgação das ações do Plano; com a Codevasf, que passou a receber recurso para atuar no BSM-Rural por meio da disponibilização de cisternas de polietileno e insumos para projetos de bovinocultura, lavoura, mandioca, avicultura e etc. Com a Embrapa a parceria propôs ampliação das atividades prevista para o BSM-Rural e a distribuição de manivas de mandioca (mudas); a Epamig, por sua vez, agência de pesquisa estadual se dispôs a participar articulando projetos. É 
interessante observar que estas três instituições mais a Emater/MG e um grupo de professores/pesquisadores da Unimontes compuseram também o que eles chamaram de Rede Geral, que se tratou de um grupo de instituições que se organizaram em prol de projetos de desenvolvimento agrícola para a região.

Veja abaixo a sistematização da rede de parceiros dos atores implementadores do Plano Brasil Sem Miséria Rural no norte do estado de Minas Gerais (cf. figura 3).

Figura 3 - A rede de implementação do BSM-Rural no Território Serra Geral (MG)

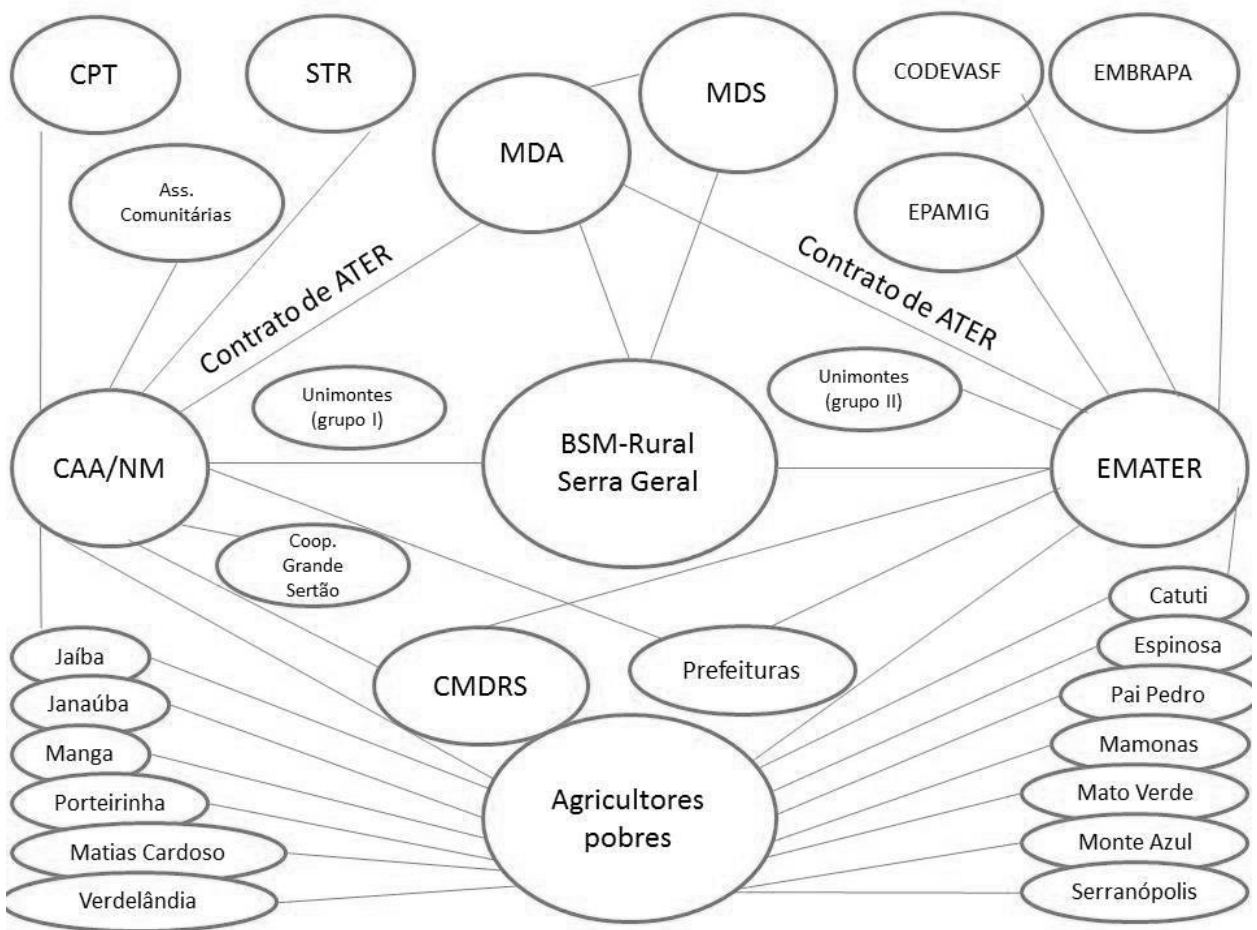

Fonte: Elaborado pela autora, com base nos dados da pesquisa de campo, agosto de 2015.

É importante destacar que tal Rede já existia, e com a chegada do BSMRural, principalmente com algumas dessas instituições recebendo recurso para atuar no Plano, o grupo visibilizou a oportunidade de estimular a articulação de novos projetos. Assim, as instituições visualizaram que o momento permitia condições para formularem novos compromissos entre eles mesmos.

\section{CONSIDERAÇÕES FINAIS}

Imbuído pelo desafio de pensar a territorialização das políticas públicas de enfrentamento da pobreza rural no Brasil, a partir do caso do Plano Brasil Sem Miséria, e na perspectiva de fugir das referências monetárias utilizadas frequentemente e da centralidade do papel do Estado nos estudos sobre pobreza, este trabalho apresentou a abordagem de Pierre Lascoumes e Patrick Le Galès de, a partir dos instrumentos da ação pública, compreender a apropriação e a tradução 
de suas ferramentas no âmbito do território, atribuindo agência aos sujeitos da implementação e, por sua vez, mediação aos atores que não somente humanos. Dessa forma, este trabalho analisou a implementação do Plano Brasil Sem Miséria, cujas ações estiveram direcionadas ao rural e se referiu especificamente à inclusão produtiva, observando a articulação de dois dos seus instrumentos: a assistência técnica e extensão rural e o Programa Fomento, no que concerniu especialmente às primeiras atividades de implementação, no norte do estado de Minas Gerais, em 2013.

Nesse sentido, analisando a formulação, a apropriação e a tradução da lista dos beneficiários, buscou-se compreender se os sistemas locais de ação pública produzidos pelo processo de implementação constituíam-se das redes sociotécnicas existentes no norte do estado de Minas Gerais. Considerando a limitação que os dados apresentavam no momento da escrita deste trabalho, ficou evidente, entretanto,(i) que a implementação do BSM-Rural foi gestionada por redes distintas, embora não completamente isolada uma da outra;(ii) que houve conexões entre elas, espaços de encontro de atores, de negociação e mediação de conflitos e, sobretudo, de aprendizado. Os dados de campo, por sua vez, sugeriram(iii) que o conflito de ideias e interesses - constituidores das redes, sejam elas sociais, técnicas ou políticas- são explicativos também do contexto de desafios do território, onde portadores de perspectivas de desenvolvimento disputam a construção de espaços de ação. Por outro lado, muitos destes desafios parecem se configurar também em torno de questões que não foram aprofundadas aqui como o acesso à terra, à água e à biodiversidade desembocando, quiçá, em perspectivas de desenvolvimento para o território e em formas distintas de mobilização entre os atores e redes.

As redes de parceiros de cada uma das instituições de ATER ao se encontrarem no espaço de ação constrangido pelo BSM-Rural mudaram procedimentos, criaram formas de resolver os problemas, reforçaram pontos de vista e venceram os seus próprios limites. Neste espaço pouco estruturado, os jogos de poder organizacionais são externos e internos às instituições combinando atividades cognitivas e normativas com normas de interpretação, negociação e resolução de conflitos naquilo que os autores chamam de dimensão da tradução e apropriação do programa público. O modo como a política pública de redução da pobreza rural foi apropriada no território Serra Geral, a partir do tratamento do público, do tempo e lugar e da mobilização de atores em redes sociotécnicas, permitiu apreender algumas das dimensões explicativas da territorialização da ação pública ao mostrar formas e impactos promovidos pela implementação nas ordens locais.

O espaço de ação constituído pelas práticas dos atores em um tempo e lugar determinado, permeado de controvérsias, negociações, conflitos e aprendizagens, oportunizou apropriações dispersas de um mesmo procedimento, seguido de momento de redefinição. Para os autores da sociologia da ação pública, o centro da implementação é a produção de sistemas locais de ação pública, porém, no norte de Minas Gerais, a pesquisa sobre a implementação mostrou além da produção desses sistemas, mostrou também que os sistemas pressionaram uns aos outros, disputaram a construção do espaço de ação e descortinaram as transformações que a ação pública pretendia introduzir exatamente por evidenciar que em sua base estão redes sociotécnicas existentes, a priori, no território.

Finalmente, acontribuição teórica de Lascoumes e Le Galès mostrou um caminho profícuo para se pensar a territorialização da ação pública ao se analisar a implementação por meio de como os atores implementadores se apropriam e traduzem as ferramentas da política pública, e pôde evidenciar como os sistemas locais de ação pública são constituídos das redes sociotécnicas existentes 
localmente. As formas de se apropriar e traduzir as ferramentas mostraram como a ação pública se faz ao ser territorializada pelas redes sociotécnicas e ao impactar as ordens locais, contribuindo para um debate articulado entre enfrentamento da pobreza e desenvolvimento territorial.

\section{REFERÊNCIAS}

AMADO, J. Região, Sertão, Nação. In: Estudos históricos. 1995, Rio de Janeiro. v. 8 , n. 15 , p. $145-151$.

ANASTASIA, C. M. J. Potentados e Bandidos: os motins do São Francisco in: Revista do Departamento de História. 1989, Belo Horizonte: UFMG, n. 9, p. 74-85.

BONNAL, P. Referências e considerações para o estudo e a atuação dos programas de desenvolvimento territorial: (PRONAT e PTC) na perspectiva da redução da pobreza em territórios rurais. In: MIRANDA, C.; TIBURCIO, B. (Org.). Políticas de desenvolvimento territorial e enfrentamento da pobreza rural no Brasil. v.19. ed. Brasília: IICA, 2013. Cap. 1. p. 33-56. (Desenvolvimento Rural Sustentável).

BRASIL. Decreto ํo 7492, de 02 de junho de 2011. Institui o Plano Brasil Sem Miséria. Brasília, DF, Disponível em: <http://www.planalto.gov.br/ccivil_03/_ato20112014/2011/Decreto/D7492.htm\#art2>. Acesso em: 27 mar. 2015.

BRASIL. Decreto ํ 7644, de 16 de dezembro de 2011. Regulamenta o Programa de Fomento às Atividades Produtivas Rurais, instituído pela Lei n. 12.512, de 14 de outubro de 2011. Brasília, DF, Disponível em: <http://www.planalto.gov.br/ccivil_03/_ato2011-2014/2011/Decreto/D7644.htm>. Acesso em: 27 mar. 2015.

DAYRELL, C. A. Geraizeiros e biodiversidade no norte de Minas: a contribuição da agroecologia e da etnoecologia nos estudos dos agroecossistemas tradicionais. 1998. 192 f. Dissertação (Mestrado) - Curso de Maestria En Agroecologia y Desarrollo Rural Sostenible, Universidade Internacional de Andalucia, La Rábida, 1998.

HALL, P. The role of interests, institutions and ideas in the comparative political economy of the industrialized nations. In: LICHBAK, M. I.; ZUCHERMAN, A. S. (org), Comparative politics, rationality, culture and structure. Cambridge: University Press, 1997.

LATOUR, B. Jamais fomos modernos. Rio de Janeiro: Editora 34, 1994.

LATOUR, B. Petites leçons de sociologie des sciences. Paris: La Découverte. Point Seuil, 2003.

LASCOUMES P.; LE GALÈS P. (ORG.) Gouverner par les instruments, Paris: Presses de Sciences-Po, 2004.

LASCOUMES P.; LE GALÈS P. Sociologie de l'action publique: domaines er approches. Paris: Armand Colin, 2. Ed., 2012. 
LEITE, S. P. Introdução. In: MIRANDA, C.; TIBURCIO, B. (Org.). Políticas de desenvolvimento territorial e enfrentamento da pobreza rural no Brasil. v.19. ed. Brasília: IICA, 2013. Cap. 4. p. 27-32. (Desenvolvimento Rural Sustentável).

MATA-MACHADO, B. N. História do sertão noroeste de Minas Gerais (16901930). 1991, Belo Horizonte: Imprensa Oficial.

MATTEI, L. Pobreza e política de desenvolvimento territorial: noções, metodologias de mensuração e estratégias de enfrentamento do problema. In: MIRANDA, C.; TIBURCIO, B.(Org.). Políticas de desenvolvimento territorial e enfrentamento da pobreza rural no Brasil. v.19. ed. Brasília: IICA, 2013. Cap. 3. p. 89-124. (Desenvolvimento Rural Sustentável).

MINISTÉRIO DO DESENVOLVIMENTO SOCIAL. Plano Brasil Sem Miséria: Caderno de Resultados 2011/2014. Brasília: MDS, 2105. 42 p.

NOGUEIRA, M. C. R. Gerais a dentro e a fora: identidade e territorialidade entre Geraizeiros do norte de Minas Gerais. 2009. 233 f. Tese (Doutorado) - Curso de Antropologia Social, Departamento de Departamento de Antropologia, Universidade de Brasília, Brasília, 2009.

SILVA, T. C.; CAPORAL, F. R. Lei de assistência técnica e extensão rural em Alagoas-Brasil: contribuições ou descontinuidade? Extensão Rural, Santa Maria, v.23, n.2, p.7-26, abr./jun. 2016. Disponível em: $<$ https://periodicos.ufsm.br/extensaorural/article/view/21288/pdf>. Acesso em: 20 set. 2017. 